\title{
All-Optical Interrogation of Neural Circuits
}

\author{
Valentina Emiliani, ${ }^{1}$ Adam E. Cohen, ${ }^{2,3}$ Karl Deisseroth,,${ }^{4,5}$ and Michael Häusser ${ }^{6,7}$ \\ ${ }^{1}$ Neurophotonics Laboratory, CNRS UMR 8250, Paris Descartes University, 75270 Paris Cedex 06, France, Departments of ${ }^{2}$ Chemistry and Chemical Biology \\ and ${ }^{3}$ Physics, Howard Hughes Medical Institute and Harvard University, Cambridge, Massachusetts 02138, ${ }^{4}$ Department of Bioengineering and ${ }^{5}$ Howard \\ Hughes Medical Institute, Stanford University, Stanford, California 94305, and ${ }^{6}$ Wolfson Institute for Biomedical Research and ${ }^{7}$ Department of \\ Neuroscience, Physiology and Pharmacology, University College London, London WC1E 6BT, United Kingdom
}

There have been two recent revolutionary advances in neuroscience: First, genetically encoded activity sensors have brought the goal of optical detection of single action potentials in vivo within reach. Second, optogenetic actuators now allow the activity of neurons to be controlled with millisecond precision. These revolutions have now been combined, together with advanced microscopies, to allow "all-optical" readout and manipulation of activity in neural circuits with single-spike and single-neuron precision. This is a transformational advance that will open new frontiers in neuroscience research. Harnessing the power of light in the all-optical approach requires coexpression of genetically encoded activity sensors and optogenetic probes in the same neurons, as well as the ability to simultaneously target and record the light from the selected neurons. It has recently become possible to combine sensors and optical strategies that are sufficiently sensitive and cross talk free to enable single-actionpotential sensitivity and precision for both readout and manipulation in the intact brain. The combination of simultaneous readout and manipulation from the same genetically defined cells will enable a wide range of new experiments as well as inspire new technologies for interacting with the brain. The advances described in this review herald a future where the traditional tools used for generations by physiologists to study and interact with the brain — stimulation and recording electrodes — can largely be replaced by light. We outline potential future developments in this field and discuss how the all-optical strategy can be applied to solve fundamental problems in neuroscience.

Key words: optogenetics; calcium imaging; wavefront shaping; two-photon microscopy; genetically encoded voltage sensor; genetically encoded calcium sensor

\section{Significance Statement}

This review describes the nexus of dramatic recent developments in optogenetic probes, genetically encoded activity sensors, and novel microscopies, which together allow the activity of neural circuits to be recorded and manipulated entirely using light. The optical and protein engineering strategies that form the basis of this "all-optical" approach are now sufficiently advanced to enable single-neuron and single-action potential precision for simultaneous readout and manipulation from the same functionally defined neurons in the intact brain. These advances promise to illuminate many fundamental challenges in neuroscience, including transforming our search for the neural code and the links between neural circuit activity and behavior.

\section{Introduction}

The advantages of using light for reading out and manipulating activity are obvious (Scanziani and Häusser, 2009): it is noninva-

\footnotetext{
Received Aug. 2, 2015; revised Sept. 8, 2015; accepted Sept. 8, 2015

This work was supported by Agence Nationale de la Recherche Grant ANR-12-BSV5-0011-01 (V.E.); NIH Grants 1-U01-NS090501-01 (V.E.), R01EB012498-02 (A.E.C.), and DP20D007428 (A.E.C.); the Féderation pour la recherche sur le cerveau (V.E.); the Rotary Club (Espoir en tête program 2012; V.E.); the Howard Hughes Medical Institute (A.E.C.); Presidential Early Career Award for Scientists and Engineers N00014-11-1-0549 (A.E.C.); the Defense Advanced Research Projects Agency Neuro-FAST program (K.D.); the NIMH (K.D.); the NIDA (K.D.); the National Science Foundation (K.D.); the Simons Foundation (K.D.); the Gatsby Foundation (K.D.); the Wiegers Family Fund (K.D.); the Nancy and James Grosfeld Foundation (K.D.); the H. L. Snyder Medical Foundation (K.D.); the Samuel and Betsy Reeves Fund (K.D.); the Vincent V. C. Woo Fund (K.D.); the Albert Yu and Mary Bechman Foundations (K.D.); the Wellcome Trust (M.H.); the Medical Research Council (M.H.); the Gatsby Charitable Foundation (M.H.); and the European Research Council (M.H.).We thank Adam Packer, Lloyd Russell, Henry Dalgleish, Eirini Papagiakoumou, Cathie Ventalon, Vivien Szabo, J. Bradley, Emiliano Ronzitti, Rossella Conti, Amanda Foust, Francesca Anselmi, Aurelien Bègue, Daniel Hochbaum, Yongxin Zhao, and Nathan Klapoetke for their contributions to the work described in this review.
}

sive and can be targeted flexibly, rapidly, and precisely to specific groups of neurons. Moreover, light is multiplexable, allowing multiple tasks to be performed by discrete wavelengths. The past decade produced twin revolutions in the use of light to probe neural function. First, on the readout side, the advent of genetically encoded sensors of voltage and calcium have brought us close to the "Holy Grail" of single-action-potential sensitivity in vivo. On the manipulation side, optogenetics now allows us to both activate and inactivate genetically defined

\footnotetext{
A.E.C. is a cofounder of Q-State Biosciences.

Correspondence should be addressed to any of the following: Valentina Emiliani, Adam E. Cohen, Karl Deisseroth, or Michael Häusser at the above addresses. E-mails: valentina.emiliani@parisdescartes.fr, cohen@chemistry.harvard.edu deissero@stanford.edu, orm.hausser@ucl.ac.uk.

D01:10.1523/JNEUROSCI.2916-15.2015

Copyright $\odot 2015$ the authors $\quad 0270-6474 / 15 / 3513917-10 \$ 15.00 / 0$
} 


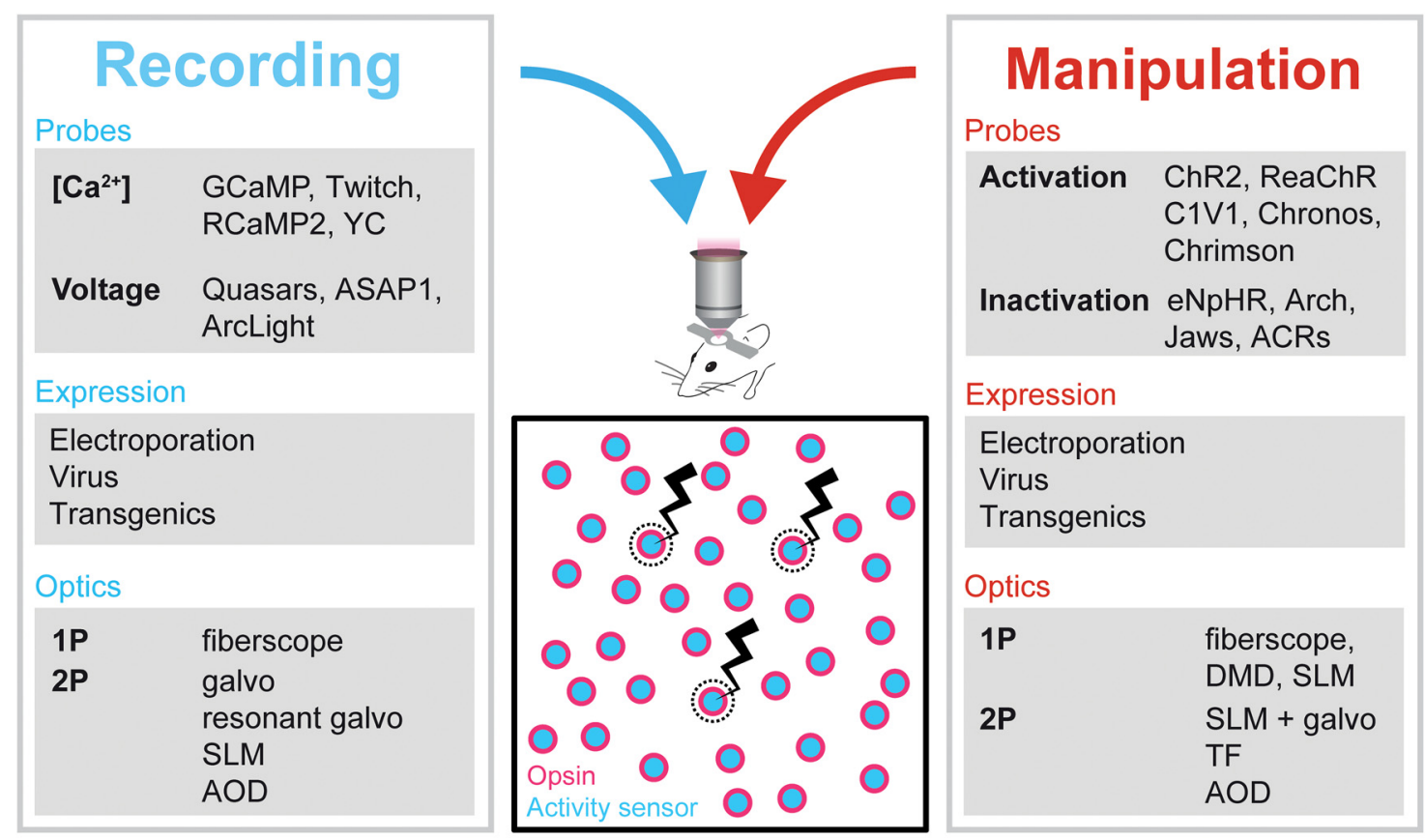

Figure 1. The toolkitfor all-optical interrogation of neural circuits. A schematic outline of the different ingredients required for the all-optical approach is shown. galvo, galvanometer; ACRs, anion channel rhodopsins; Arch, archaerhodopsin; YC, yellow chameleon; A0D, acousto-optic deflector.

populations of neurons with millisecond precision, even on the level of single neurons. However, these two revolutions have proceeded more or less in parallel, and it has proven very difficult to combine readout and manipulation of the same cells, and thus achieve fully "all-optical" interrogation of neural activity.

Implementations of simultaneous optical readout and manipulation have faced three main challenges: reliable delivery and expression of the sensors and actuators in the same neurons, elimination of cross talk between the imaging and manipulation channels, and achieving recording and manipulation each with single-neuron and single-action-potential precision. Early efforts to combine imaging and one-photon (1P) optogenetic manipulation involved the use of nongenetic indicators of activity such as the calcium sensors fura-2 (Zhang et al., 2007) or Fluo-5F (Zhang and Oertner, 2007), or the voltage sensor RH-155 (Airan et al., 2007). This strategy was more recently implemented in vivo to examine the functional properties of interneuron networks (Wilson et al., 2012), map interhemispheric and intrahemispheric connectivity (Lim et al., 2012), and probe motor pattern generation during behavior (Fajardo et al., 2013). In these experiments, spectral overlap of the actuator excitation and readout emission wavelengths was typical, resulting in data loss during the crucial photostimulation period. The combination of optogenetic actuator expression with a red-shifted genetically encoded calcium sensor has allowed simultaneous recording and photostimulation to be performed in the same circuit from genetically identified populations of neurons in Caenorhabditis elegans (Akerboom et al., 2013). Early efforts to deal with the lack of spatial precision achievable with one-photon optogenetic activation involved targeting light using digital micromirror devices (DMDs; Zhu et al., 2012), though this approach is unlikely to provide single-cell resolution in vivo, or by combining simultaneous holographic imaging and photostimulation methods relying on glutamate uncaging (Niko- lenko et al., 2007; Dal Maschio et al., 2010; Anselmi et al., 2011), which lacks genetic specificity. Moreover, none of these approaches has provided true single-action-potential and single-neuron resolution for simultaneous readout and manipulation, particularly in vivo.

Here we first describe the various ingredients required for achieving reliable and precise all-optical interrogation of neural circuits (Fig. 1), then present some early results obtained using this approach, and finally discuss future perspectives.

\section{Probes for readout}

Neural activity produces little endogenous optical contrast. Simply by looking at a neuron, one cannot observe its firing, although researchers have long sought means to detect a fast intrinsic optical signal (FIOS) induced by changes in membrane potential. A FIOS has been detected via subtle changes in optical birefringence (Cohen, 1973), cell shape (Oh et al., 2012), and, recently, stimulated Raman scattering (Liu et al., 2015). FIOS imaging typically requires only a very narrow spectral band and can be performed with near infrared light. Thus, it is attractive for avoiding cross talk in combination with optogenetic stimulation. However, to date these signals remain small and difficult to distinguish from activity-independent cell motion, which will be particularly problematic in vivo and in densely packed tissue. Thus, most researchers rely on contrast agents.

\section{Genetically encoded calcium sensors}

By far the most widely used reporters of neural activity rely on detection of $\mathrm{Ca}^{2+}$. Action potentials lead to opening of voltagegated calcium channels, and thus to an elevation in cytoplasmic $\mathrm{Ca}^{2+}$ concentration, typically from 50-100 nM to 5-10 $\mu \mathrm{M}$ (Grienberger and Konnerth, 2012). The $\mathrm{Ca}^{2+}$ transient decays over 100-500 ms. Genetically encoded calcium indicators (GECIs) are now sufficiently sensitive to report single-actionpotential $\mathrm{Ca}^{2+}$ transients (Fig. $2 A$ ). 

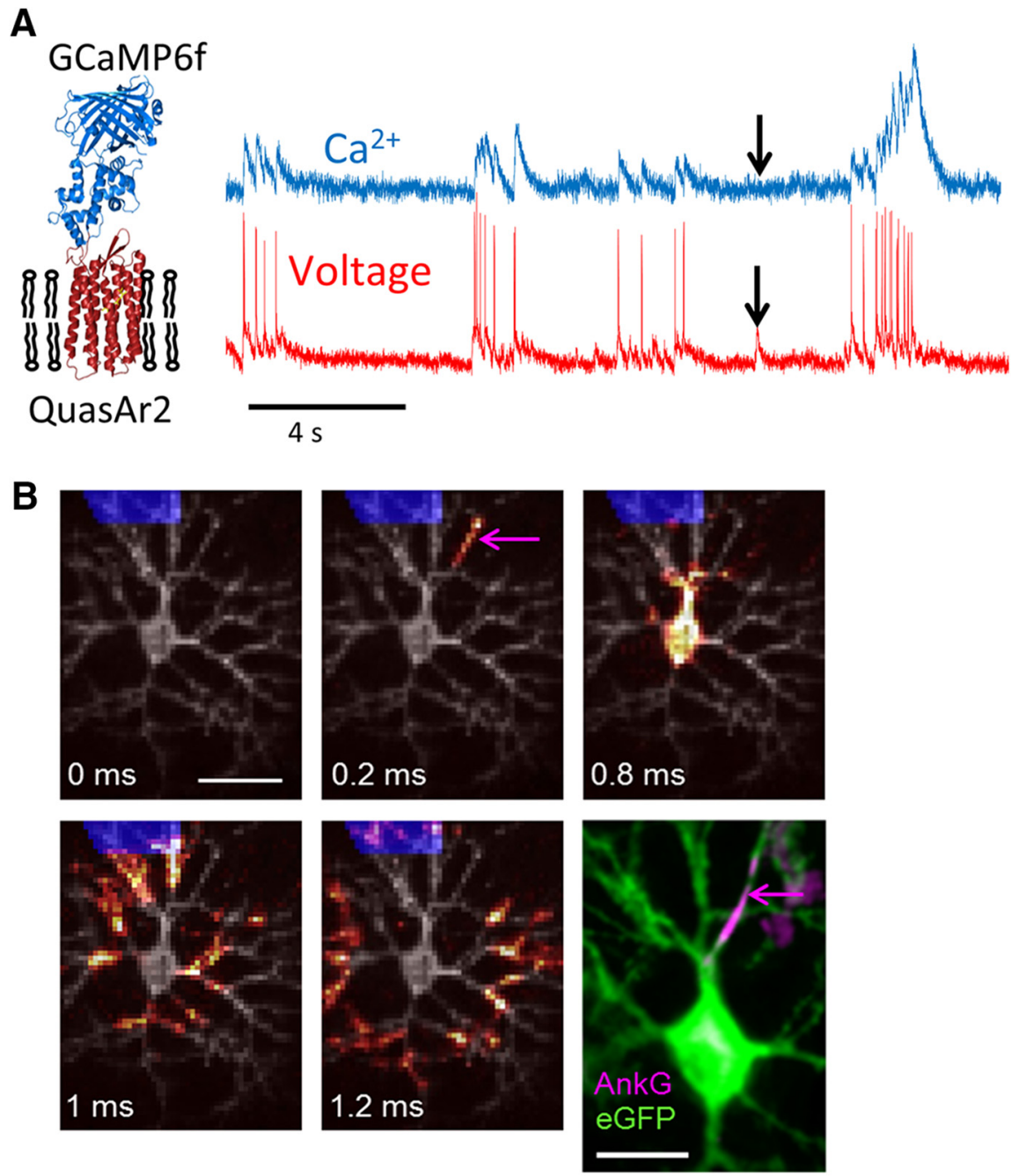

C
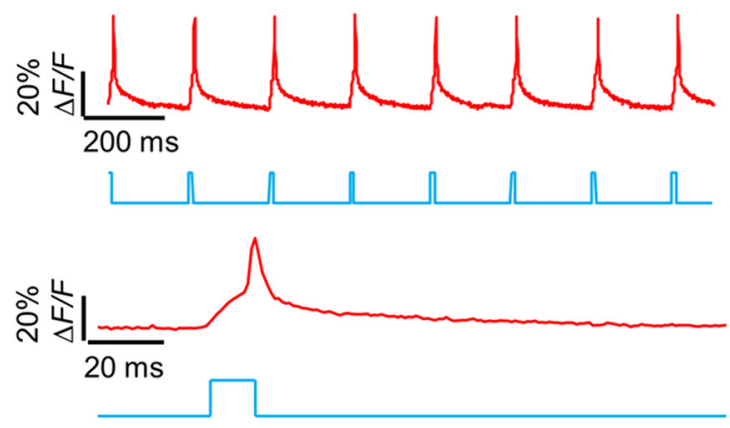

Figure 2. All-optical electrophysiology. A, Comparison of fluorescence signals recorded simultaneously from a GECl, GCaMP6f, and a GEVI, QuasAr2, expressed as a fusion construct in a rat hippocampal neuron. Subthreshold depolarizations, such as indicated by the arrow, do not have a correlate in the $\mathrm{Ca}^{2+}$ signal. $\boldsymbol{B}$, Spatially resolved all-optical electrophysiology in a cultured rat hippocampal neuron. The blue region indicates the optically stimulated patch of dendrite. The action potential initiated in an unstimulated process and propagated back into the soma and into the dendritic arbor. Movie frames were calculated by subNyquist interpolation of data acquired at a $1 \mathrm{~s}$ exposure time. Scale bar, $50 \mu \mathrm{m}$. Bottom right, Immunostaining of the same cell with anti-EGFP (EGFP; green) and anti-AnkyrinG (AnkG; magenta). Scale bar, $25 \mu \mathrm{m}$. Magenta arrows, Site of action potential initiation; distal end of the axon initial segment. C, Single-trial optical recordings of APs initiated by pulses of blue illumination (10 $\mathrm{ms}, 7.5 \mathrm{~mW} / \mathrm{cm}^{2}$ ). Signal represents whole-soma fluorescence without photobleaching correction or background subtraction (modified from Hochbaum et al., 2014).

All GECIs use a $\mathrm{Ca}^{2+}$-induced conformational change in a sensing domain, typically calmodulin or troponin. FRET-based GECIs offer the prospect of increased accuracy through ratiometric sensing (Thestrup et al., 2014), but the reliance on two fluo- rophores may require too much spectral bandwidth for easy combination with optogenetic actuators. Single-fluorophore GECIs, one recently useful example of which is the GCaMP6 family (Chen et al., 2013), have become popular for their sensitivity, brightness, and robust twophoton (2P) signals.

With the advent of red-shifted optogenetic actuators such as C1V1 (Yizhar et al., 2011), ReaChR (Lin et al., 2013), and Chrimson (Klapoetke et al., 2014), one can combine these actuators with GCaMP Ca ${ }^{2+}$ indicators (spectrally similar to EGFP) for simultaneous stimulation and recording. However, cross talk remains a problem: all channelrhodopsin variants have a long tail on the blue side of their action spectrum, leading to $20-30 \%$ of peak activation at wavelengths used to excite EGFP (Venkatachalam and Cohen, 2014). Two-photon stimulation and imaging can minimize this cross talk by taking advantage of the different subcellular distributions of the GECI and the channelrhodopsin.

Several groups have worked on developing red-shifted $\mathrm{Ca}^{2+}$ indicators, with the aim to combine them with blueshifted optogenetic actuators or with EGFP-based reporters. The R-GECO1 reporter (Zhao et al., 2011) shows good sensitivity, but experiences photoconversion into a bright state upon blue light illumination (Wu et al., 2013), hindering its use with optogenetic actuators. Recently, a flurry of new red-shifted GECIs have been developed. R-CaMP2 shows good sensitivity and speed, and an expanded dynamic range compared to other singlefluorophore GECIs (Inoue et al., 2015). Other improved variants jRGECOla, jRCaMP1a, and jRCaMP1b are available on Addgene (http://www.addgene.org/ browse/article/9406/), but are not yet published (see http://janelia.org/sites/default/ files/SfN2014_red_GECIs_ver6.pdf). It is not yet established whether these reporters are excited sufficiently far to the red and have sufficiently small blue light photoactivation for robust cross-talk-free alloptical neural interfacing.

Finally, recently developed luminescent $\mathrm{Ca}^{2+}$ indicators suggest an alternate route to cross-talk-free interfacing (Takai et al., 2015). These reporters do not require optical excitation, and can therefore be readily paired with optogenetic actuators. Further advances in brightness will likely be necessary for this approach to become practical.

In all neurons, spiking leads to an increase in $\mathrm{Ca}^{2+}$ concentration. But not all increases in $\mathrm{Ca}^{2+}$ concentration come from spiking, and moreover, subthreshold but functionally important changes in membrane voltage often have no corresponding $\mathrm{Ca}^{2+}$ 
signal. Intracellular $\mathrm{Ca}^{2+}$ concentration is regulated spatially and temporally by a complex array of channels and transporters (for review, see Grienberger and Konnerth, 2012). Furthermore, the relationship between spike rate and cytoplasmic $\mathrm{Ca}^{2+}$ concentration is nonlinear, the expression level of a GECI is rarely known precisely, the relation between cytoplasmic $\mathrm{Ca}^{2+}$ concentration and reporter fluorescence is nonlinear, and, moreover, we currently lack a completely reliable spike inference algorithm. Finally, single action potentials may not be easily optically discernible with calcium sensors in neurons with high firing rates, and in particular fast spiking interneurons. Thus, in vivo $\mathrm{Ca}^{2+}$ imaging using GECIs is currently primarily used as a qualitative tool to determine which cells are activated by a temporally defined stimulus.

\section{Genetically encoded voltage sensors}

Voltage imaging in neurons has been a goal of neuroscientists for nearly 50 years (Peterka et al., 2011). Genetically encoded voltage indicators (GEVIs) based on fusions of a fluorescent protein to a voltage-sensing domain (St-Pierre et al., 2015) have reached a sensitivity of $\sim 35 \%$ per $100 \mathrm{mV}$ in the ArcLight scaffold (Jin et al., 2012), and response times as short as $2 \mathrm{~ms}$ in ASAP1 (St-Pierre et al., 2014). A recently introduced variant, Bongwoori (Piao et al., 2015), shows improved speed ( $8 \mathrm{~ms}$ response time) relative to ArcLight and sensitivity comparable to ASAP1. The ASAP1 protein is fast enough to report single action potentials in cultured neurons with high signal-to-noise ratio. As with the GECIs, spectral overlap between channelrhodopsins and the GFP-based GEVIs hinders simultaneous readout and manipulation. GEVIs based on red-shifted fluorescent proteins are in development and may be appropriate for use with blue-shifted channelrhodopsin variants.

A second class of GEVIs is based on modified microbial rhodopsin proton pumps. Changes in membrane voltage modulate the weak fluorescence of the retinylidene chromophore. These GEVIs show response amplitudes of up to $~ 90 \%$ per $100 \mathrm{mV}$ in QuasAr2 (Fig. 2) and response speeds of $0.05 \mathrm{~ms}$ in QuasAr1 (Hochbaum et al., 2014). Rhodopsin-based GEVIs are excited by red light and emit in the near infrared, enabling simultaneous use with optogenetic actuators, with minimal optical cross talk. However, the low brightness of these probes has been an obstacle to applications in vivo. One can enhance the brightness of these GEVIs via voltage-dependent quenching of an appended fluorescent protein (Gong et al., 2014; Zou et al., 2014). This electrochromic FRET (eFRET) approach sacrifices some of the speed and sensitivity of the endogenous retinal fluorescence, and thus far has not matched the signal-to-noise ratio of the endogenous retinal fluorescence. However, eFRET can be used to create GEVIs with a range of colors, and thus may be an approach to simultaneous optical stimulation and readout. Hybrid sensors based on simultaneous use of a membrane-targeted fluorescent protein and a voltage-responsive quencher [hybrid voltage sensor (hVOS)] have shown promising results in brain slices (Ghitani et al., 2015). The far blue excitation of this system (430 nm) may enable simultaneous use with a red-shifted channelrhodopsin.

Photobleaching and phototoxicity are more severe challenges with voltage imaging than with $\mathrm{Ca}^{2+}$ imaging. Voltage transients are $\sim 100$-fold briefer than $\mathrm{Ca}^{2+}$ transients. Thus, to achieve similar photon counts-and hence similar levels of shot noise-a voltage indicator must be excited with a much greater illumination intensity. This challenge is likely to remain severe for all GEVIs derived from GFP and its homologues.

\section{Probes for manipulation}

Neuroscientists currently have available a substantial (and growing) diversity of optogenetic control tools. Of these, a subset have been demonstrated to be suitable for all-optical experimentation in vivo thanks to their spectral properties or two-photon excitation characteristics.

\section{Probes for activation of neurons}

Robust two-photon optogenetic activation of neurons, originally demonstrated with channelrhodopsin-2 (ChR2; Rickgauer and Tank, 2009), has been observed with red-light-activated C1V1 variants (Packer et al., 2012, 2015; Prakash et al., 2012; Bègue et al., 2013; Rickgauer et al., 2014), which allow integration with the GCaMP series of reporter tools. However, certain blue-lightactivated channelrhodopsins can also be recruited powerfully enough to easily control spiking by raster-scanning two-photon illumination (especially those with the T159C mutation; Prakash et al., 2012, their Supplemental Fig. 4d). Blue-light-activated channelrhodopsins have also been combined for all-optical experiments with R-CaMP2 in C. elegans (Inoue et al., 2015).

Many other optogenetic control tools have not yet been tested or published with regard to two-photon or all-optical experiments in tissue, though we anticipate that several known optogenetic actuators with high photocurrents and moderately slow kinetics (greater than $\sim 30 \mathrm{~ms}$ inactivation time constant) will also be found suitable, as with C1V1. Efforts to narrow or shift action spectra for both indicators and actuators represent an active and highly valuable area of research. Hence, development and testing of opsins across all spectral bands will be crucial for realizing the full potential of all-optical neuroscience.

\section{Probes for inactivation and modulation of neurons}

Although many optogenetic inhibitory tools are available, thus far only eArch3.0 (Mattis et al., 2012) has been reported to be robustly recruited by two-photon illumination; Prakash et al. (2012) showed it could block action potentials generated by current injection in vitro. As with excitatory tools, the membrane trafficking peptide-enhanced high expression (Gradinaru et al., 2010; Mattis et al., 2012) and some degree of temporal integration at the cellular level likely contribute together to observed utility during two-photon excitation. However, this pump has not yet been reported to be useful in all-optical experiments; its greenlight-activated action spectrum peak overlaps heavily with the visible-spectrum $\mathrm{Ca}^{2+}$ indicators, posing challenges for alloptical experiments despite robust two-photon responsiveness.

Red-light-activated inhibitors such as eNpHR3.0 (Gradinaru et al., 2010) and Jaws (Chuong et al., 2014) may be suitable for all-optical experiments, though overlap with activity indicators in the blue and green will still require careful attention to minimize optical cross talk. A more useful all-optical strategy might involve blue-light-driven inhibitors alongside R-CaMP2, although such a combination has not yet been reported. Particularly interesting in this regard might be the new blue-light-driven inhibitory chloride channels, dubbed anion channel rhodopsins (Berndt et al., 2014; Wietek et al., 2014; Govorunova et al., 2015), integrated with R-CaMP2 under one- or two-photon control.

Distinct from inhibition, longer-timescale modulation of target cells may also be useful in all-optical experiments, for example, in the step-function opsin approaches described above. New step-function opsins have been developed for two-photon control in intact tissue (Prakash et al., 2012), and biochemical modulator-based optogenetic tools also in principle could be used for long-timescale modulation, including the optoXRs 
A

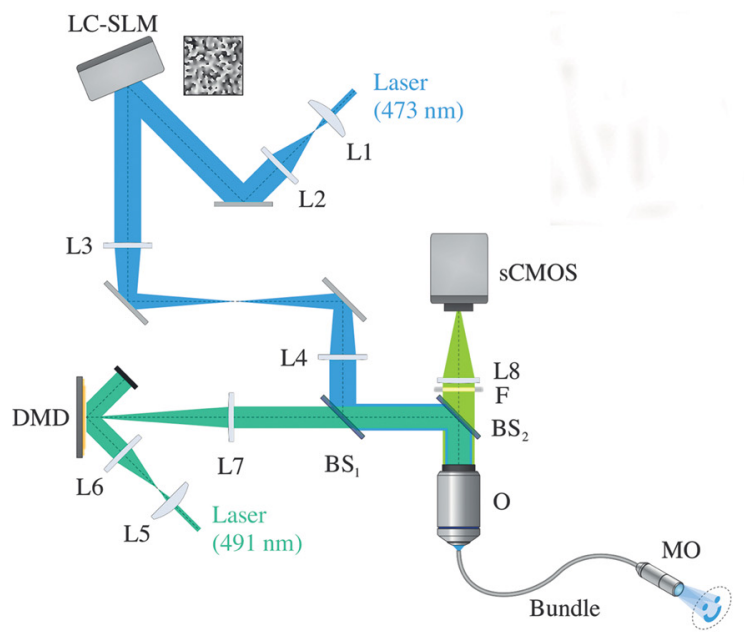

B

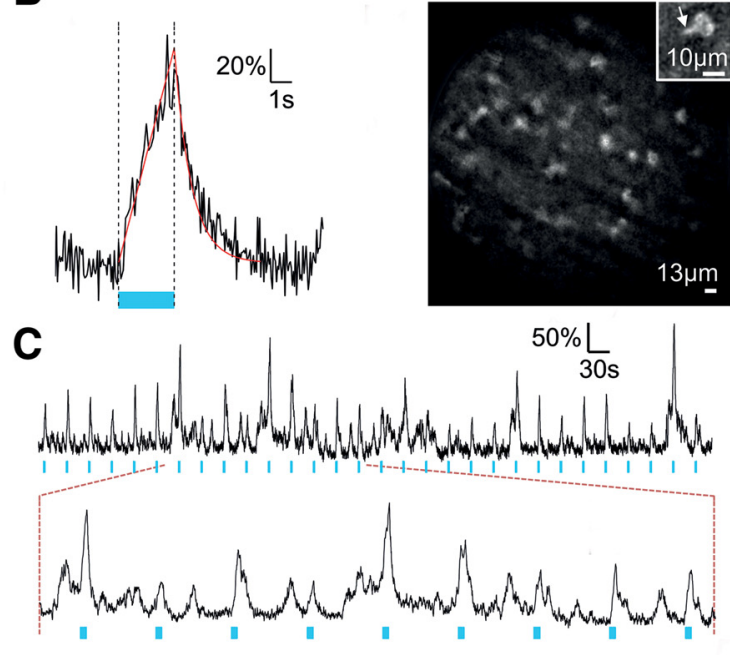

Figure 3. Patterned photostimulation and functional imaging in freely behaving mice. A, Schematic of the holographic fiberscope composed of two illumination paths: one for photoactivation with CGH including a liquid-crystal spatial light modulator, and a second for fluorescence imaging including a DMD. Backward fluorescence was detected on a scientific complementary metal oxide semiconductor (sCMOS) camera. Both paths were coupled to the sample using a fiber bundle attached to a micro-objective (MO). L, Lens; BS, beam splitter; 0, microscope objective. B, Left, Calcium signal triggered by photoactivation (blue line; $p=50 \mathrm{~mW} / \mathrm{mm}^{2}$ ) with a $5 \mu \mathrm{m}$ holographic spot placed on the soma of a ChR2-expressing cell recorded in a freely behaving mouse coexpressing GCaMP5-G and ChR2 in cerebellar molecular layer interneurons (MLLs). Right, Structure illumination image recorded in a freely behaving mouse and showing MLI somata and a portion of a dendrite (inset). Scale bars: $10 \mu \mathrm{m}$. C, Top, The same photoactivation protocol as in $A$ was repeated every $30 \mathrm{~s}$ for $15 \mathrm{~min}$ (photostimulation power, $50 \mathrm{~mW} / \mathrm{mm}^{2}$; imaging power, $0.28 \mathrm{~mW} / \mathrm{mm}^{2}$ ). Bottom, Expansion of the top trace showing that spontaneous activity frequently occurs between evoked transients (adapted from Szabo et al., 2014).

(Airan et al., 2009). Valuable next steps in this regard will be further engineering to shift action spectra of the step-function opsins and the optoXRs.

\section{Optical methods for patterned photostimulation}

The small single-channel conductance of actuators such as ChR2 ( $~ 80$ fS; Feldbauer et al., 2009) in combination with activation within the femtoliter two-photon focal volume means that the resulting current is generally not sufficient to bring a neuron to firing threshold. This has prompted the development of photostimulation approaches that aim to increase the excitation volume. They can be grouped in two main categories: scanning and parallel excitation techniques.

\section{Scanning methods}

Laser scanning methods use galvanometric mirrors, resonant scanners, or acousto-optic devices to quickly scan a laser beam across several positions. Using this approach, Rickgauer and Tank (2009) provided the first demonstration of action potential generation with two-photon excitation in cultured cells.

With scanning approaches, the temporal resolution for the photostimulation of $N$ cells can be expressed as $T_{s}=n \times\left(R_{t}+\right.$ $\left.S_{t}\right) \times N$, where $n$ is the number of positions visited within each cell, and $R_{t}$ and $S_{t}$ are the dwell and scanning times, respectively. Optogenetic probe properties including maximum photocurrent, channel open time, two-photon excitation cross-section, and expression density determine the minimal dwell time, $R_{t}$, required to optimally actuate molecules within the focal volume. Desensitization and decay time of the channel determine the optimal scanning time, $S_{t}$, for efficient temporal current integration. By scanning a decreased numerical aperture (NA) Gaussian beam in a spiral trajectory covering the cell's surface, Rickgauer and Tank (2009) were able to generate action potentials with $30 \mathrm{~ms}$ temporal resolution. Temporal current integration with serial scanning can be improved by using opsins such as C1V1 featuring slow tau off and nanoampere-scale currents. Using this approach, two-photon action potential generation was demonstrated pre- viously in acute slices and in vivo with a temporal resolution for single cell excitation ranging between 5 and 70 ms (Packer et al., 2012; Prakash et al., 2012). However, the use of slow opsins combined with a scanning approach limits the achievable temporal precision of photostimulation with evoked spikes associated with significant jitter; a recent estimate of in vivo jitter with spiral scanning is $5.6 \pm 0.8 \mathrm{~ms}$ (Packer et al., 2015).

Improved temporal resolution and precision can be achieved by underfilling the objective back aperture, which enables increasing the spot size and therefore reducing the number of scanning positions. Using temporal focusing (TF) enables compensation of the consequent deterioration in axial resolution, which is inversely proportional to the square of NA. Briefly, in $\mathrm{TF}$, a grating is used to diffract the different frequencies comprising the ultrashort excitation pulse toward different directions. The various frequencies thus propagate toward the objective focal plane at different angles, such that the pulse is temporally smeared above and below the focal plane, which remains the only region irradiated at peak powers efficient for two-photon excitation (Oron et al., 2005). Combined with a two-photon scanning microscope, TF enabled fast photostimulation of multiple cells in vitro and in vivo (Andrasfalvy et al., 2010; Rickgauer et al., 2014). For excitation spots covering the whole cell body, temporal resolution can be reduced to $T_{s}=\left(R_{t}+S_{t}\right) \times N$ (Rickgauer et al., 2014).

\section{Parallel illumination methods}

The need to rapidly stimulate multiple neurons as achieved with wide-field techniques while preserving the spatial targeting capability of beam-scanning systems has prompted the evolution of "parallel" illumination methods where all selected target regions are excited simultaneously. In this way, the temporal resolution for photoactivation is determined primarily by the actuator kinetics and is independent on the number of targets, that is, $T_{s}=$ $R_{t}$. The different methods are based either on the modulation of light intensity or on the modulation of the phase of a coherent beam. With amplitude modulation, light patterns are created by 
selectively blocking light that is not "ontarget," while with phase modulation, light patterns are created by "redirecting" the light onto the target allowing superior power efficiency versus amplitude modulation. Phase modulation approaches such as computer-generated holography (CGH) or generalized phase contrast (GPC) achieve phase modulation through the use of liquid-crystal-based spatial light modulators (LC-SLMs). More precisely, in CGH a Fourier-based iterative algorithm is used to compute the phase pattern at the rear aperture of the objective that permits production of the desired target intensity in the objective focal plane. The calculated phase hologram is addressed to a LC-SLM that imposes the phase modulation onto the input beam wavefront. After propagation through the objective, the beam is focused onto an intensity pattern, reproducing the desired template. Several recent reports implemented computergenerated holography for neuronal activation via one-photon and two-photon glutamate uncaging (Lutz et al., 2008; Nikolenko et al., 2008; Dal Maschio et al., 2010; Zahid et al., 2010; Anselmi et al., 2011; Yang et al., 2011) and actuation of opsin-expressing neurons in vitro and in vivo (Packer et al., 2012, 2015; Bègue et al., 2013; Szabo et al., 2014). CGH can also generate threedimensional multipoint illumination patterns, a feature demonstrated to perform multitrap optical tweezing (Curtis et al., 2002) and 3D glutamate uncaging (Yang et al., 2011; Go et al., 2012). Adding lens-phase modulations to 2D phase holograms also enables remote axial displacement and 3D positioning of laterally shaped targets (Sinclair et al., 2004; Zahid et al., 2010).

CGH pattern generation suffers from "speckles," which are a consequence of the iterative algorithm modulating only the phase of the laser beam, allowing the phase at the sample plane to vary as a free parameter. Speckle fluctuations reach $20 \%$ in one-photon and 50\% in two-photon CGH implementations. Alternatively, applications requiring precise control of light distribution within the illumination area can use the GPC approach, an interferometric method originally proposed for multitrap optical tweezers used previously to generate speckle-free two-photon extended shapes.

When combined with TF, both CGH and GPC also showed robust propagation through scattering media, well preserving axial resolution and overall shape at depths up to $500 \mu \mathrm{m}$ (Papagiakoumou et al., 2013). The combination of CGH and GPC with TF has enabled reliable in vitro AP generation in single and multiple cells or cellular processes with high spatiotemporal resolution using ChR2 (Papagiakoumou et al., 2010) or C1V1 (Bègue et al., 2013). CGH combined with the use of Rickgauer et al., 2014).
B

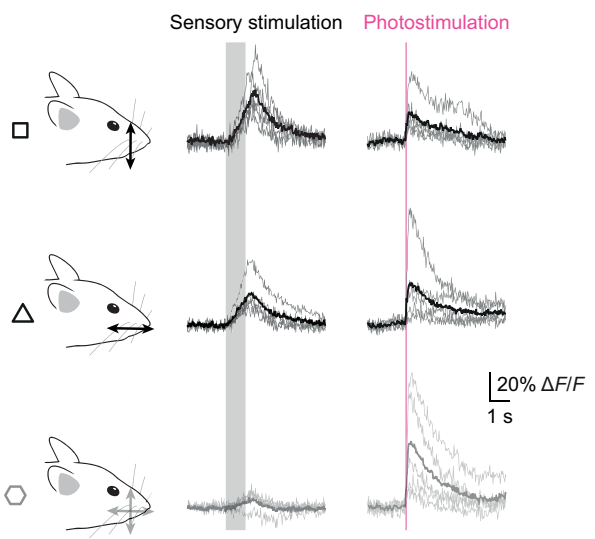

D

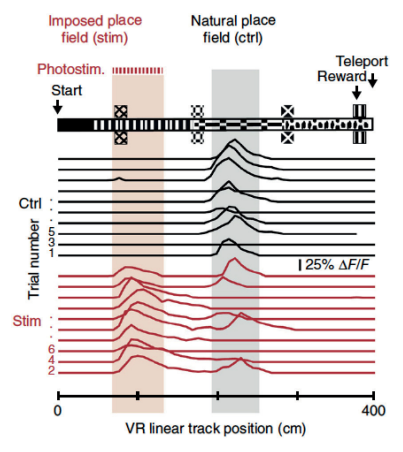

Figure 4. Targeting manipulation to functionally defined ensembles of neurons. $A$, A field of view showing neurons coexpress( (g)een) and C1V1(E122T/E162T)-2A-EYFP (red) in an awake mouse. Inset, Images (EYFP; top panels) and a pseudocolor merge (bottom; image sizes, imental examples of place cell perturbation. A trained mouse ran along a $400 \mathrm{~cm}$ virtual reality track (top). A neuron with (gray shaded region) was stimulated while the mouse ran through a different part of the track (red stimulation (red; Stim) traversals. Place-specific stimulation mimicked the activity observed in the place field (adapted from

the fast opsin Chronos also enabled AP generation with millisecond temporal precision, submillisecond jitter $(0.1 \pm 0.01$ $\mathrm{ms})$, and fast spiking rate $(100 \mathrm{~Hz})$ in interneurons from layer $2 / 3$ of visual cortex (E. Ronzitti, R. Conti, V. Zampini, N. Klapoetke, D. Tanese, E. Boyden, and V. Emiliani, unpublished observations).

CGH and other phase-based light-patterning methods divide available laser power among all targets in a specific pattern. Therefore, the available total laser power could limit the maximum number of targets achievable. A good compromise between temporal resolution $\left[T_{s}=n \times\left(R_{t}+S_{t}\right)\right]$ and the achievable number of neurons per stimulation could be reached by combining 2D and 3D CGH beam splitting with spiral scanning, as shown by Packer et al., (2012, 2015).

\section{Simultaneous readout and manipulation with single-cell precision}

Successful combination of the various elements of the all-optical toolkit described above has only been achieved in the past year. 
Crucial to simultaneous all-optical readout and manipulation is the minimization of cross talk between the recording and stimulation channels, which requires judicious selection of sensors and actuators with different wavelength spectra (as discussed above), combined with the use of the appropriate filters and careful titration of input power. An alternative approach to eliminating optical cross talk takes advantage of the complex photophysics of microbial rhodopsin-based optogenetic actuators. Step function opsins are opened by blue light, but closed by orange light (Berndt et al., 2009). Thus, one can use continuous blue illumination to image a GECI such as GCaMP6 (or any other GFPbased reporter) and modulated orange illumination to negatively regulate the activity of the step function opsin (Venkatachalam and Cohen, 2014). This "stoplight" approach has been demonstrated in single neurons in vitro, but not yet in slice or in vivo.

The closest approach toward all-optical electrophysiology to date has been provided by coexpression of a highly efficient optogenetic actuator (CheRiff) with the new QuasAr voltage indicators. This combination enables simultaneous optical perturbation and sensitive and fast readout of membrane voltage (Hochbaum et al., 2014). This approach, termed "Optopatch," has enabled optical characterization of cellular excitability in large numbers of cultured neurons (Fig. $2 B, C$ ). Patterned stimulation of CheRiff was also used in optical studies of action potential propagation and synaptic transmission. Further developments are required to implement this approach in vivo.

Several recent studies have combined a genetically encoded calcium indicator with an optogenetic probe for all-optical interrogation in vivo. Two groups (Rickgauer et al., 2014; Packer et al., 2015) combined two-photon population calcium imaging with two-photon optogenetics to achieve simultaneous readout and manipulation with single-cell and single-action-potential precision in head-fixed awake mice in vivo. Rickgauer et al. (2014) used TF to target manipulation to individual CA1 pyramidal cells, enabling them to bias place cell firing during navigation in virtual reality. In contrast, Packer et al. (2015) used an SLM to target multiple functionally characterized cells for simultaneous photoactivation. In a complementary approach, a holographic fiberscope was developed by coupling an SLM into a fiber with an objective, combining it with one-photon calcium imaging with a micromirror array also delivered to the fiber, which allows simultaneous photoactivation and readout with near-cellular resolution in freely moving mice (Fig. 3; Szabo et al., 2014). Finally, the development of the new red GECI RCaMP2 has allowed bluelight-activated channelrhodopsins to be combined with readout of activity in freely moving C. elegans (Inoue et al., 2015). Together, these experiments have demonstrated the viability of alloptical interrogation in a range of experimental applications for manipulation of neural circuits in behaving animals. The next steps will be to engineer order-of-magnitude improvements in the different elements of the all-optical toolkit-most notably, the parallel development of new sensors and actuators with nonoverlapping wavelength spectra and the refinement of optical strategies for light targeting of multiple cells deep in tissue while minimizing excitation of "out-of-focus" neurons expressing the actuators-and then to assess which stimulation strategies (scanning versus parallel) are best suited to different types of experiments.

\section{Applications}

There are many practical reasons why all-optical interrogation is of substantial value for a wide range of applications. The utility of all-optical experimentation lies in achieving concurrent population-level control and readout from genetic or functionally defined circuit elements. This approach leverages the advantages of light not only for its ability to target cells expressing optical sensors and actuators, but also its minimally invasive qualities, speed, and multiple-communication-channel spectral opportunities. Here we outline several exciting applications of this approach that can be anticipated in the coming years as the techniques become widely implemented.

First, coexpression of the optical indicator with the optogenetic actuator allows tracking of recruitment of the same genetically defined target cells, using both sensing and control together. Such validation of the effectiveness of intervention is important for any optogenetic experiment, but also could be helpful for quantitative matching of target-cell recruited activity to the level normally exhibited by the target cell population during natural behavior in the same animal. Many groups have now achieved such useful coexpression for all-optical experiments during behavior in mammals (Rickgauer et al., 2014; Szabo et al., 2014; Grosenick et al., 2015; Packer et al., 2015). Moreover, this approach also allows the impact of perturbations to be evaluated on activity in the local network, and in principle allows functional connectivity patterns to be probed during different behavioral states. The combination of optogenetic probes with emerging high-sensitivity voltage sensors may eventually even enable subthreshold connectivity patterns to be measured by reading out EPSPs or IPSPs in monosynaptically connected cells.

Second, if the optical reporter of activity is genetically delivered to a different population of cells instead of (or in addition to) the optogenetically actuated circuit element, realtime observation of elicited circuit dynamics at the definedcell level becomes possible. Even though behavioral and electrical readouts have been implemented for many years in optogenetics, a long-sought dream experiment involves also reading out the activity in real time of specific cell populations thought to be involved in the behavior-in the presence or absence of precise optogenetic modulation. Rajasethupathy (2015) recently achieved this configuration in behaving mammals, using a novel axonally trafficked red-light-activated opsin to control afferent projections to hippocampus while also observing local cellular dynamics in hippocampus with GCaMP6m, all in animals undergoing contextual memory testing.

Third, all-optical experiments bring exciting new opportunities for closed-loop control of neural circuits. Historically, system feedback in optogenetics had been achieved chiefly with electrical or behavioral system readouts (Sohal et al., 2009; Leifer et al., 2011; Stirman et al., 2011; O'Connor et al., 2013; Paz et al., 2013; Krook-Magnuson et al., 2014; Siegle and Wilson, 2014; Grosenick et al., 2015; Newman et al., 2015). However, optical feedback from a genetically targeted population could allow real-time adjustment of optogenetic input to achieve a desired waveform of activity in the controlled population in vivo during behavior, accounting for all of the system variability associated with varying brain states, activity history, local field potential (LFP) rhythm phase, and so on. Moreover, testing models of the circuit itself becomes much more swift and rigorous with closed-loop methods for system identification. Extracting useful information (to be fed back in the closed loop) from imaging data is computationally harder (and slower, problematically so for this question) than with a single time-varying scalar that the electrical readouts such as LFP provide. However, even as computational methods prog- 
ress, a useful intermediate step is enabled by fiber photometry (Gunaydin et al., 2014; Grosenick et al., 2015). In this method, a genetically defined population activity value is collapsed to a single time-varying scalar that is as easy to work with as an LFP, but reports the activity of the genetically targeted circuit element in real time concurrently with control (Grosenick et al., 2015).

Finally, the tools being developed for the all-optical approach applied to basic research questions may in the future have a widespread impact for both diagnosis and treatment of CNS diseases. Two potential areas of particular interest are their application in high-throughput optical bioassays of disease status and functional mechanisms in tissue explants or in patient-derived neurons obtained through induced pluripotent stem cells, and in the development of new brain-machine interfaces that could combine both readout and selective activation of the same circuits.

\section{Conclusions and perspective}

All-optical interrogation offers a new paradigm for probing the functional properties of neural circuits and for understanding the causal relationships between activity in defined neuronal ensembles and behavior. Crucially, it enables the targeting of neurons based on their functional signature, rather than their genetic or anatomical properties (Fig. 4). Moreover, it allows the consequences of perturbations in the local network to be read out in real time, enabling one to close the loop between readout of activity patterns, modulation of these patterns, and behavior. Ultimately, by enabling neural circuits to be both recorded and manipulated with the spatial and temporal precision on which they operate during behavior, this approach should yield new insights into the nature of the neural code.

The dominant tools for probing neural circuits over the past century have been the stimulation and recording electrodes, which offer unparalleled temporal resolution and exquisite sensitivity, but which generally lack spatial resolution when implemented in vivo, as well as the ability to rapidly target multiple identified cells. We anticipate that because of its power and flexibility, the all-optical approach will rapidly supplant electrophysiological approaches for a range of different questions, both for basic neuroscience research as well as for translational investigation. However, for many applications, electrophysiological approaches will continue to be irreplaceable (Scanziani and Häusser, 2009), most notably for probing very fast interactions between neurons or brain areas (for which the temporal resolution of imaging approaches remains inadequate), for voltage-clamp recording of synaptic and voltage-gated currents, and for simultaneous recording of activity across multiple neural circuits. Indeed, we anticipate that the combination of all-optical and electrophysiological approaches will provide a very fruitful intersection for future experiments.

\section{References}

Airan RD, Hu ES, Vijaykumar R, Roy M, Meltzer LA, Deisseroth K (2007) Integration of light-controlled neuronal firing and fast circuit imaging. Curr Opin Neurobiol 17:587-592. CrossRef Medline

Airan RD, Thompson KR, Fenno LE, Bernstein H, Deisseroth K (2009) Temporally precise in vivo control of intracellular signalling. Nature 458: 1025-1029. CrossRef Medline

Akerboom J, Carreras Calderón N, Tian L, Wabnig S, Prigge M, Tolö J, Gordus A, Orger MB, Severi KE, Macklin JJ, Patel R, Pulver SR, Wardill TJ, Fischer E, Schüler C, Chen TW, Sarkisyan KS, Marvin JS, Bargmann
CI, Kim DS, et al. (2013) Genetically encoded calcium indicators for multi-color neural activity imaging and combination with optogenetics. Front Mol Neurosci 6:2. CrossRef Medline

Andrasfalvy BK, Zemelman BV, Tang J, Vaziri A (2010) Two-photon singlecell optogenetic control of neuronal activity by sculpted light. Proc Natl Acad Sci U S A 107:11981-11986. CrossRef Medline

Anselmi F, Ventalon C, Bègue A, Ogden D, Emiliani V (2011) Threedimensional imaging and photostimulation by remote-focusing and holographic light patterning. Proc Natl Acad Sci U S A 108:19504-19509. CrossRef Medline

Bègue A, Papagiakoumou E, Leshem B, Conti R, Enke L, Oron D, Emiliani V (2013) Two-photon excitation in scattering media by spatiotemporally shaped beams and their application in optogenetic stimulation. Biomed Opt Express 4:2869-2879. CrossRef Medline

Berndt A, Yizhar O, Gunaydin LA, Hegemann P, Deisseroth K (2009) Bistable neural state switches. Nat Neurosci 12:229-234. CrossRef Medline

Berndt A, Lee SY, Ramakrishnan C, Deisseroth K (2014) Structure-guided transformation of channelrhodopsin into a light-activated chloride channel. Science 344:420 -424. CrossRef Medline

Chen TW, Wardill TJ, Sun Y, Pulver SR, Renninger SL, Baohan A, Schreiter ER, Kerr RA, Orger MB, Jayaraman V, Looger LL, Svoboda K, Kim DS (2013) Ultrasensitive fluorescent proteins for imaging neuronal activity. Nature 499:295-300. CrossRef Medline

Chuong AS, Miri ML, Busskamp V, Matthews GA, Acker LC, Sorensen AT, Young A, Klapoetke NC, Henninger MA, Kodandaramaiah SB, Ogawa M, Ramanlal SB, Bandler RC, Allen BD, Forest CR, Chow BY, Han X, Lin Y, Tye KM, Roska B, et al. (2014) Noninvasive optical inhibition with a red-shifted microbial rhodopsin. Nat Neurosci 17:1123-1129. CrossRef Medline

Cohen LB (1973) Changes in neuron structure during action potential propagation and synaptic transmission. Physiol Rev 53:373-418. Medline

Curtis JE, Koss BA, Grier DG (2002) Dynamic holographic optical tweezers. Opt Commun 207:169-175. CrossRef

Dal Maschio M, Difato F, Beltramo R, Blau A, Benfenati F, Fellin T (2010) Simultaneous two-photon imaging and photo-stimulation with structured light illumination. Opt Express 18:18720-18731. CrossRef Medline

Fajardo O, Zhu P, Friedrich RW (2013) Control of a specific motor program by a small brain area in zebrafish. Front Neural Circuits 7:67. Medline

Feldbauer K, Zimmermann D, Pintschovius V, Spitz J, Bamann C, Bamberg E (2009) Channelrhodopsin-2 is a leaky proton pump. Proc Natl Acad Sci U S A 106:12317-12322. CrossRef Medline

Ghitani N, Bayguinov PO, Ma Y, Jackson MB (2015) Single-trial imaging of spikes and synaptic potentials in single neurons in brain slices with genetically encoded hybrid voltage sensor. J Neurophysiol 113:1249-1259. CrossRef Medline

Go MA, Stricker C, Redman S, Bachor HA, Daria VR (2012) Simultaneous multi-site two-photon photostimulation in three dimensions. J Biophotonics 5:745-753. CrossRef Medline

Gong Y, Wagner MJ, Zhong Li J, Schnitzer MJ (2014) Imaging neural spiking in brain tissue using FRET-opsin protein voltage sensors. Nat Commun 5:3674. Medline

Govorunova EG, Sineshchekov OA, Janz R, Liu X, Spudich JL (2015) Natural light-gated anion channels: a family of microbial rhodopsins for advanced optogenetics. Science 349:647-650. CrossRef Medline

Gradinaru V, Zhang F, Ramakrishnan C, Mattis J, Prakash R, Diester I, Goshen I, Thompson KR, Deisseroth K (2010) Molecular and cellular approaches for diversifying and extending optogenetics. Cell 141:154-165. CrossRef Medline

Grienberger C, Konnerth A (2012) Imaging calcium in neurons. Neuron 73:862-885. CrossRef Medline

Grosenick L, Marshel JH, Deisseroth K (2015) Closed-loop and activityguided optogenetic control. Neuron 86:106-139. CrossRef Medline

Gunaydin LA, Grosenick L, Finkelstein JC, Kauvar IV, Fenno LE, Adhikari A, Lammel S, Mirzabekov JJ, Airan RD, Zalocusky KA, Tye KM, Anikeeva P, Malenka RC, Deisseroth K (2014) Natural neural projection dynamics underlying social behavior. Cell 157:1535-1551. CrossRef Medline

Hochbaum DR, Zhao Y, Farhi SL, Klapoetke N, Werley CA, Kapoor V, Zou P, Kralj JM, Maclaurin D, Smedemark-Margulies N, Saulnier JL, Boulting GL, Straub C, Cho YK, Melkonian M, Wong GK, Harrison DJ, Murthy VN, Sabatini BL, Boyden ES, et al. (2014) All-optical electrophysiology in mammalian neurons using engineered microbial rhodopsins. Nat Methods 11:825-833. CrossRef Medline 
Inoue M, Takeuchi A, Horigane S, Ohkura M, Gengyo-Ando K, Fujii H, Kamijo S, Takemoto-Kimura S, Kano M, Nakai J, Kitamura K, Bito H (2015) Rational design of a high-affinity, fast, red calcium indicator R-CaMP2. Nat Methods 12:64-70. Medline

Jin L, Han Z, Platisa J, Wooltorton JR, Cohen LB, Pieribone VA (2012) Single action potentials and subthreshold electrical events imaged in neurons with a fluorescent protein voltage probe. Neuron 75:779-785. CrossRef Medline

Klapoetke NC, Murata Y, Kim SS, Pulver SR, Birdsey-Benson A, Cho YK, Morimoto TK, Chuong AS, Carpenter EJ, Tian Z, Wang J, Xie Y, Yan Z, Zhang Y, Chow BY, Surek B, Melkonian M, Jayaraman V, Constantine-Paton M, Wong GK, et al. (2014) Independent optical excitation of distinct neural populations. Nat Methods 11:338-346. CrossRef Medline

Krook-Magnuson E, Szabo GG, Armstrong C, Oijala M, Soltesz I (2014) Cerebellar directed optogenetic intervention inhibits spontaneous hippocampal seizures in a mouse model of temporal lobe epilepsy. Eneuro 1:e.2014. Medline

Leifer AM, Fang-Yen C, Gershow M, Alkema MJ, Samuel AD (2011) Optogenetic manipulation of neural activity in freely moving Caenorhabditis elegans. Nat Methods 8:147-152. CrossRef Medline

Lim DH, Mohajerani MH, Ledue J, Boyd J, Chen S, Murphy TH (2012) In vivo large-scale cortical mapping using channelrhodopsin-2 stimulation in transgenic mice reveals asymmetric and reciprocal relationships between cortical areas. Front Neural Circuits 6:11. Medline

Lin JY, Knutsen PM, Muller A, Kleinfeld D, Tsien RY (2013) ReaChR: a red-shifted variant of channelrhodopsin enables deep transcranial optogenetic excitation. Nat Neurosci 16:1499-1508. CrossRef Medline

Liu B, Lee HJ, Zhang D, Liao CS, Ji N, Xia Y, Cheng JX (2015) Label-free spectroscopic detection of membrane potential using stimulated Raman scattering. Appl Physics Lett 106:173704. CrossRef

Lutz C, Otis TS, de Sars V, Charpak S, DiGregorio DA, Emiliani V (2008) Holographic photolysis of caged neurotransmitters. Nat Methods 5:821827. CrossRef Medline

Mattis J, Tye KM, Ferenczi EA, Ramakrishnan C, O’Shea DJ, Prakash R, Gunaydin LA, Hyun M, Fenno LE, Gradinaru V, Yizhar O, Deisseroth K (2012) Principles for applying optogenetic tools derived from direct comparative analysis of microbial opsins. Nat Methods 9:159-172. Medline

Newman JP, Fong MF, Millard DC, Whitmire CJ, Stanley GB, Potter SM (2015) Optogenetic feedback control of neural activity. Elife 4:e07192. Medline

Nikolenko V, Poskanzer KE, Yuste R (2007) Two-photon photostimulation and imaging of neural circuits. Nat Methods 4:943-950. CrossRef Medline

Nikolenko V, Watson BO, Araya R, Woodruff A, Peterka DS, Yuste R (2008) SLM microscopy: scanless two-photon imaging and photostimulation with spatial light modulators. Front Neural Circuits 2:5. CrossRef Medline

O'Connor DH, Hires SA, Guo ZV, Li N, Yu J, Sun QQ, Huber D, Svoboda K (2013) Neural coding during active somatosensation revealed using illusory touch. Nat Neurosci 16:958-965. CrossRef Medline

Oh S, Fang-Yen C, Choi W, Yaqoob Z, Fu D, Park Y, Dassari RR, Feld MS (2012) Label-free imaging of membrane potential using membrane electromotility. Biophys J 103:11-18. CrossRef Medline

Oron D, Tal E, Silberberg Y (2005) Scanningless depth-resolved microscopy. Opt Express 13:1468-1476. CrossRef Medline

Packer AM, Peterka DS, Hirtz JJ, Prakash R, Deisseroth K, Yuste R (2012) Two-photon optogenetics of dendritic spines and neural circuits. Nat Methods 9:1202-1205. CrossRef Medline

Packer AM, Russell LE, Dalgleish HW, Häusser M (2015) Simultaneous alloptical manipulation and recording of neural circuit activity with cellular resolution in vivo. Nat Methods 12:140-146. Medline

Papagiakoumou E, Anselmi F, Bègue A, de Sars V, Glückstad J, Isacoff EY, Emiliani V (2010) Scanless two-photon excitation of channelrhodopsin-2. Nature Methods 7:848-854. CrossRef Medline

Papagiakoumou E, Bègue A, Leshem B, Schwartz O, Stell BM, Bradley J, Oron D, Emiliani V (2013) Functional patterned multiphoton excitation deep inside scattering tissue. Nat Photonics 7:274-278. CrossRef

Paz JT, Davidson TJ, Frechette ES, Delord B, Parada I, Peng K, Deisseroth K, Huguenard JR (2013) Closed-loop optogenetic control of thalamus as a tool for interrupting seizures after cortical injury. Nat Neurosci 16:64-70. Medline

Peterka DS, Takahashi H, Yuste R (2011) Imaging voltage in neurons. Neuron 69:9-21. CrossRef Medline

Piao HH, Rajakumar D, Kang BE, Kim EH, Baker BJ (2015) Combinatorial mutagenesis of the voltage-sensing domain enables the optical resolution of action potentials firing at $60 \mathrm{~Hz}$ by a genetically encoded fluorescent sensor of membrane potential. J Neurosci 35:372-385. CrossRef Medline

Prakash R, Yizhar O, Grewe B, Ramakrishnan C, Wang N, Goshen I, Packer AM, Peterka DS, Yuste R, Schnitzer MJ, Deisseroth K (2012) Twophoton optogenetic toolbox for fast inhibition, excitation and bistable modulation. Nat Methods 9:1171-1179. CrossRef Medline

Rajasethupathy P (2015) Projections from neocortex mediate top-down control of memory retrieval. Nature. In press. CrossRef

Rickgauer JP, Tank DW (2009) Two-photon excitation of channelrhodopsin-2 at saturation. Proc Natl Acad Sci U S A 106:15025-15030. CrossRef Medline

Rickgauer JP, Deisseroth K, Tank DW (2014) Simultaneous cellularresolution optical perturbation and imaging of place cell firing fields. Nat Neurosci 17:1816-1824. CrossRef Medline

Scanziani M, Häusser M (2009) Electrophysiology in the age of light. Nature 461:930-939. CrossRef Medline

Siegle JH, Wilson MA (2014) Enhancement of encoding and retrieval functions through theta phase-specific manipulation of hippocampus. Elife 3:e03061. Medline

Sinclair G, Leach J, Jordan P, Gibson G, Yao E, Laczik Z, Padgett M, Courtial $J$ (2004) Interactive application in holographic optical tweezers of a multi-plane Gerchberg-Saxton algorithm for three-dimensional light shaping. Opt Express 12:1665-1670. CrossRef Medline

Sohal VS, Zhang F, Yizhar O, Deisseroth K (2009) Parvalbumin neurons and gamma rhythms enhance cortical circuit performance. Nature 459: 698-702. CrossRef Medline

Stirman JN, Crane MM, Husson SJ, Wabnig S, Schultheis C, Gottschalk A, Lu H (2011) Real-time multimodal optical control of neurons and muscles in freely behaving Caenorhabditis elegans. Nat Methods 8:153-158. CrossRef Medline

St-Pierre F, Marshall JD, Yang Y, Gong Y, Schnitzer MJ, Lin MZ (2014) High-fidelity optical reporting of neuronal electrical activity with an ultrafast fluorescent voltage sensor. Nat Neurosci 17:884-889. CrossRef Medline

St-Pierre F, Chavarha M, Lin MZ (2015) Designs and sensing mechanisms of genetically encoded fluorescent voltage indicators. Curr Opin Chem Biol 27:31-38. CrossRef Medline

Szabo V, Ventalon C, De Sars V, Bradley J, Emiliani V (2014) Spatially selective holographic photoactivation and functional fluorescence imaging in freely behaving mice with a fiberscope. Neuron 84:1157-1169. CrossRef Medline

Takai A, Nakano M, Saito K, Haruno R, Watanabe TM, Ohyanagi T, Jin T, Okada Y, Nagai T (2015) Expanded palette of nano-lanterns for realtime multicolor luminescence imaging. Proc Natl Acad Sci U S A 112: 4352-4356. CrossRef Medline

Thestrup T, Litzlbauer J, Bartholomäus I, Mues M, Russo L, Dana H, Kovalchuk Y, Liang Y, Kalamakis G, Laukat Y, Becker S, Witte G, Geiger A, Allen T, Rome LC, Chen TW, Kim DS, Garaschuk O, Griesinger C, Griesbeck O (2014) Optimized ratiometric calcium sensors for functional in vivo imaging of neurons and T lymphocytes. Nat Methods 11: 175-182. CrossRef Medline

Venkatachalam V, Cohen AE (2014) Imaging GFP-based reporters in neurons with multiwavelength optogenetic control. Biophys J 107:15541563. CrossRef Medline

Wietek J, Wiegert JS, Adeishvili N, Schneider F, Watanabe H, Tsunoda SP, Vogt A, Elstner M, Oertner TG, Hegemann P (2014) Conversion of channelrhodopsin into a light-gated chloride channel. Science 344:409 412. CrossRef Medline

Wilson NR, Runyan CA, Wang FL, Sur M (2012) Division and subtraction by distinct cortical inhibitory networks in vivo. Nature 488:343-348. CrossRef Medline

Wu J, Liu L, Matsuda T, Zhao Y, Rebane A, Drobizhev M, Chang YF, Araki S, Arai Y, March K, Hughes TE, Sagou K, Miyata T, Nagai T, Li WH, Campbell RE (2013) Improved orange and red $\mathrm{Ca}(2)+/$ - indicators and photophysical considerations for optogenetic applications. ACS Chem Neurosci 4:963-972. CrossRef Medline 
Yang S, Papagiakoumou E, Guillon M, de Sars V, Tang CM, Emiliani V (2011) Three-dimensional holographic photostimulation of the dendritic arbor. J Neural Eng 8:046002. CrossRef Medline

Yizhar O, Fenno LE, Prigge M, Schneider F, Davidson TJ, O'Shea DJ, Sohal VS, Goshen I, Finkelstein J, Paz JT, Stehfest K, Fudim R, Ramakrishnan C, Huguenard JR, Hegemann P, Deisseroth K (2011) Neocortical excitation/inhibition balance in information processing and social dysfunction. Nature 477:171-178. CrossRef Medline

Zahid M, Vélez-Fort M, Papagiakoumou E, Ventalon C, Angulo MC, Emiliani V (2010) Holographic photolysis for multiple cell stimulation in mouse hippocampal slices. PLoS One 5:e9431. CrossRef Medline

Zhang F, Wang LP, Brauner M, Liewald JF, Kay K, Watzke N, Wood PG, Bamberg E, Nagel G, Gottschalk A, Deisseroth K (2007) Multimodal fast optical interrogation of neural circuitry. Nature 446:633-639. CrossRef Medline
Zhang YP, Oertner TG (2007) Optical induction of synaptic plasticity using a light-sensitive channel. Nat Methods 4:139-141. CrossRef Medline

Zhao Y, Araki S, Wu J, Teramoto T, Chang YF, Nakano M, Abdelfattah AS, Fujiwara M, Ishihara T, Nagai T, Campbell RE (2011) An expanded palette of genetically encoded $\mathrm{Ca}(2)(+)$ indicators. Science 333:18881891. CrossRef Medline

Zhu P, Fajardo O, Shum J, Zhang Schärer YP, Friedrich RW (2012) Highresolution optical control of spatiotemporal neuronal activity patterns in zebrafish using a digital micromirror device. Nat Protoc 7:1410-1425. CrossRef Medline

Zou P, Zhao Y, Douglass AD, Hochbaum DR, Brinks D, Werley CA, Harrison DJ, Campbell RE, Cohen AE (2014) Bright and fast multicoloured voltage reporters via electrochromic FRET. Nat Commun 5:4625. Medline 